\title{
México: políticas industriales y producción de bienes y servicios de tecnologías de la información y la comunicación
}

\author{
Claudia Schatan y Leobardo Enriquez
}

RESUMEN

En este estudio se investiga hasta qué punto el auge digital ha repercutido en la actividad productiva, la manufactura (bienes TIC) y los servicios TIC, además de sus potenciales ramificaciones en el resto de la economía mexicana. Se utilizan las matrices de insumoproducto (MIP) y se hace referencia a las del Brasil y los Estados Unidos de América. México se ha rezagado, especialmente en la producción de bienes TIC, y las cadenas productivas de esta actividad se han debilitado. El sector de servicios TIC ofrece un potencial mucho mayor que el aprovechado hasta ahora, con la ventaja de incorporar comparativamente mayor valor agregado y con grandes posibilidades de diversificación. Se considera primordial encontrar políticas industriales más efectivas enfocadas en los sectores de bienes y servicios TIC, lo que constituye un desafío, sobre todo si se observan países como el Brasil con enfoques más proactivos, pero con resultados mixtos.

PALABRAS CLAVE

CLASIFICACIÓN JEL

AUTORES
Tecnología de la información, tecnología de las comunicaciones, comercio de servicios, bienes de consumo, producción industrial, política industrial, México, Brasil

C67, L63, L86, L98, O14, O25

Claudia Schatan es Consultora Independiente. claudiaschatan8@gmail.com

Leobardo Enríquez es Miembro del Grupo de Análisis Estructural de la Facultad de Economía, Universidad Nacional Autónoma de México (Unam), y Funcionario del Consejo Nacional de Ciencia y Tecnología (сONACYT). leobardo.enriquez@gmail.com 


\section{I}

\section{Introducción}

Las tecnologías de la información y las comunicaciones (TIC) cumplen un papel central en la actual tendencia a nivel mundial a la conectividad entre las personas, el almacenamiento de una cantidad cada vez mayor de información en menos espacio, la facilitación y diversificación de las actividades financieras, el enriquecimiento de las actividades recreacionales, la simplificación y mayor accesibilidad a los trámites del gobierno, y la extensión de los servicios de salud y de la educación, entre otras contribuciones.

Existe un amplio debate acerca de la repercusión que pueden tener las TIC en el desarrollo económico y su potencial para que los países rezagados puedan avanzar más rápidamente al desarrollo (Niebel, 2014). El principal interés del presente estudio radicará en analizar hasta qué punto el auge digital ha estimulado la actividad productiva en el sector de manufacturas (bienes TIC) y de servicios (servicios TIC) en México. Más específicamente, mediante la utilización de las matrices de insumo-producto (MIP) se indaga si el sistema productivo ha aprovechado cabalmente el dinamismo que caracteriza a la esfera de las TIC, así como sus potenciales ramificaciones en el resto de la economía. Como punto de referencia, para este análisis se toman las experiencias del Brasil y los Estados Unidos de América, aunque también hay referencias, más puntuales, a otros países como China. Asimismo, en el estudio se investiga si las políticas públicas seguidas en México han tenido un papel relevante para potenciar el efecto del avance de las TIC en la actividad productiva, con cuyo fin se toma en consideración la experiencia brasileña. La hipótesis es que México muestra un relativamente lento avance en la producción de bienes y servicios TIC y en su uso por parte de los demás sectores productivos, lo que señala que el modelo de política industrial que se ha seguido ha sido insuficiente.

Desde el punto de vista de la producción, la industria electrónica es la mayor fabricante de bienes de consumo en el mundo, mientras que los equipos con que se

Agradecemos enormemente el apoyo, la orientación y los comentarios de Martín Puchet, así como el interés, las conversaciones y los comentarios de Isidro Soloaga. Cualquier error es de entera responsabilidad de los autores. produce en las empresas tienen un componente digital cada vez mayor. Junto con la industria de hardware se desarrolla aún más rápidamente la industria de servicios de información, que incluye el diseño de sistemas operativos, el de telecomunicaciones, el procesamiento de datos, servicios en la nube, la minería de datos, entre otros (Sturgeon y Kawakami, 2010).

La revolución de las TIC en la esfera productiva ha cambiado la forma de diseñar, organizar, procesar, distribuir y comercializar los productos manufacturados y los servicios. Durante el proceso de producción mismo, las TIC facilitan la interconexión entre las distintas etapas de producción, incluidos la optimización de los sistemas de distribución y transporte o el apoyo en el diseño y pruebas del producto, entre ellos la fabricación asistida por computadoras (CAM, por sus siglas en inglés).

Además, la incorporación de las TIC de manera horizontal en la economía se percibe en la enorme variedad de productos y servicios TIC que forman parte de otros productos: robots, Sistema de Posicionamiento Global (GPS), cámaras de video, Bluetooth, videos, videojuegos, entre otros. El contenido de TIC es cada vez mayor incluso en las industrias tradicionales, como el sector textil y el agropecuario (McNamara, 2008).

Si este tema se enfoca desde el punto de vista de las matrices de insumo-producto, las TIC deberían ser una parte cada vez más importante de los encadenamientos productivos. En una economía globalizada, estas interacciones sectoriales en aumento pueden no registrarse a nivel nacional, sino a nivel internacional, lo que se reflejaría en un mayor comercio de partes y piezas de bienes y de servicios TIC. Sin embargo, si un país logra desarrollar un importante sector productivo de bienes y servicios TIC, este puede tener un efecto dinámico en la economía nacional.

En la sección II del estudio se analizará la posición de México en la producción de bienes y de servicios TiC con respecto a otros países; en la sección III se indaga el papel de estos sectores en la generación de valor agregado (va) y el empleo en la economía mexicana (en comparación con las del Brasil y de los Estados Unidos de América). En la cuarta sección se examinará el papel de estos mismos sectores en las operaciones intermedias de la economía, en contraste con el Brasil y los Estados Unidos de América. Asimismo, se observarán 
los encadenamientos productivos hacia adelante y hacia atrás generados por los sectores analizados dentro de la economía mexicana y teniendo como puntos de referencia a los países ya mencionados. En la sección $\mathrm{V}$ del estudio se revisarán algunas de las políticas industriales que se han aplicado a los sectores de bienes y servicios TIC en el Brasil y México. Finalmente, en la sexta sección se presentarán algunas reflexiones finales.

\section{II}

\section{Situación comparada de México con otros países en la producción de bienes y de servicios TIC}

\section{Acceso a las TIC}

Para contextualizar el desarrollo del sector de las TIC en México es importante considerar las condiciones específicas que enfrenta este sector allí y compararlas con las de otras naciones teniendo en cuenta, a la vez, la dinámica del mercado global de estos bienes y servicios.

Lo primero que salta a la vista es que el país tiene comparativamente poco acceso a las TIC, tanto desde el punto de vista de los individuos como de las empresas, lo que limita la extensión y profundidad de los mercados TIC. En el país no se han hecho las inversiones suficientes a fin de que se cuente con un adecuado acceso a dichas tecnologías. Para el sector productivo el acceso a banda ancha, y por lo tanto a Internet, es esencial si se procura optimizar su competitividad para acceder a mercados, hacer innovación tecnológica, mejorar la capacitación y los servicios financieros, entre otros avances. En un estudio de CEPAL (2013) se evidencia, por ejemplo, que el rezago en uso de banda ancha móvil en México se debe principalmente a una oferta deficientes inversiones en redes $3 \mathrm{G}$.

Los problemas de infraestructura también se aprecian en el hecho de que México no ofrece un acceso a Internet de banda ancha fija a una velocidad comparable con la del resto de los países de la Organización para la Cooperación y el Desarrollo Económicos (OCDE), donde en 2011 más del 70\% del acceso a Internet era con alta o muy alta velocidad. En el Brasil, esta cifra era del $40 \%$ en ese año, mientras que en México no existía tal velocidad de acceso (ORBA, 2011).

Asimismo, en México el costo de la suscripción a la banda ancha (fija y móvil) ha sido comparativamente elevado, en contraste con la gran mayoría de los países de la OCDE (OCDE, 2014).

Las limitaciones mencionadas, además de la falta de capacitación de una parte importante de la población en materia digital, explica que el acceso de las empresas mexicanas a la banda ancha sea la más baja entre los países de la OCDE: solo el $50 \%$ de las empresas con 10 empleados o más tenían tal acceso en México en 2012 (OCDE, 2014) ${ }^{1}$.

En comparación con otros 148 países a nivel mundial, México se ubica en un lugar nada competitivo de acuerdo con el índice del grado de preparación (IGP) de los países para beneficiarse del desarrollo de las TIC del Foro Económico Mundial (lugar 79 en 2014). El contraste es particularmente agudo con su vecino, los Estados Unidos de América, que se encuentran en el lugar 7, y con varios países nórdicos de Europa que ocupan los primeros lugares.

Pero al contrastar a México con otros países en desarrollo como China, el Brasil y la India, la posición de México no es tan diferente de estos. Se encuentra algo por debajo del Brasil (lugar 69) y China (lugar 62), pero se ubica por sobre la India (lugar 83). Esta fuente atribuye la situación específica de México a la ausencia de una agenda digital holística, junto con el alto costo de las telecomunicaciones y los bajos estándares educacionales. La India, que se ha convertido en la principal exportadora mundial de servicios TIC, tiene un fuerte rezago en infraestructura y aunque es el país donde el acceso a las TIC es el más asequible internacionalmente, su uso individual es de los más limitados del mundo. Si bien el Brasil y México tienen un IGP similar, resulta interesante observar que el Brasil cuenta comparativamente con una mejor infraestructura y un uso considerablemente más elevado de las TIC por parte de la población y las empresas, lo que permite entender que exista un mercado interno brasileño comparativamente mayor, como se verá en las siguientes secciones. China, a su vez, presenta varios subindicadores similares a los de

\footnotetext{
${ }^{1}$ Véase el oEcD Broadband Portal [en línea] http://www.oecd.org/sti/ broadband/oecDbroadbandportal.htm.
} 
México, pero cuenta con mayores destrezas y un uso más generalizado de las TIC, especialmente por parte de las empresas (comparable al Brasil) ${ }^{2}$. De todas formas, el va en la demanda final global de bienes TIC de China y México era muy bajo comparado con los provenientes de Alemania, el Japón y los Estados Unidos de América, al menos hasta 2009, de acuerdo con la información manejada por la OCDE (2014).

2 Véase Foro Económico Mundial, 2014 [en línea] http://www3.weforum. org/docs/WEF_GlobalInformationTechnology_Report_2014.pdf.
Es importante señalar que el contexto institucional no ha favorecido el desarrollo adecuado del sector de TIC en México debido a las prácticas monopólicas ejercidas en este sector, especialmente en telecomunicaciones, y los pocos instrumentos con los que ha contado el sector público para evitarlas. Ha habido avances importantes en materia legislativa, especialmente la nueva Ley de Telecomunicaciones, que incluye una nueva institución a cargo de vigilar la adecuada competencia en este mercado. Sin embargo, aun esta nueva ley tiene carencias importantes en cuanto a la independencia de los organismos públicos que operan en este ámbito.

\section{III \\ Producción de las TIC en México, el Brasil y los Estados Unidos de América}

El comportamiento de los sectores productores de bienes y de servicios TIC en cada país no es independiente de lo que ocurre a nivel mundial. Entre otros fenómenos, hay que considerar el desplazamiento de la producción de manufacturas TIC desde los países de la OCDE hacia los países asiáticos y la reducción del peso específico de los bienes TIC respecto de otros productos, debido a la caída en sus precios relativos. El sector de servicios TIC, en contraste, ha cobrado especial dinamismo en los países de la OCDE como resultado de la mayor demanda por aplicaciones y manejo de infraestructura de la tecnología de la información (OCDE, 2014).

Es necesario tener en cuenta que la distinción entre la producción de bienes TIC y servicios TIC es cada vez más difícil de hacer. De hecho, las empresas proveedoras de servicios empresariales, los fabricantes de hardware, las telecomunicaciones y los desarrolladores de software tienden a converger y la distinción entre estas dos grandes agrupaciones de bienes y servicios se está desdibujando y siguiendo la dinámica de la innovación tecnológica; efectivamente, todos se inclinan por producir más servicios.

En esta sección se analizará la producción de manufacturas y de servicios Tic para tres países: México, el principal objeto de este estudio; el Brasil, el mayor productor y consumidor de bienes y servicios TIC en América Latina y el Caribe (ALC), y los Estados Unidos de América, el principal socio comercial de México y el segundo exportador internacional de TIC después de China. A futuro sería interesante poder comparar a México con otros países emergentes, además del Brasil, para contrastar el desempeño de los sectores productivos TIC y las políticas que los acompañan, pero la disponibilidad de información de cuentas nacionales a nivel desagregado, especialmente para servicios TIC, hace muy difícil este ejercicio actualmente.

La información empleada proviene de las cuentas nacionales. Las cifras utilizadas para bienes TIC son comparables para los tres países analizados, mientras que en el segmento de servicios TIC no lo son, por lo que la comparación se hace por pares: México-Brasil y México-Estados Unidos de América. La producción de servicios TIC probablemente está subestimada sobre todo respecto de México y el Brasil, pues muchos se producen dentro de las empresas, por lo que no se comercializan y con frecuencia no se imputa su valor real, o bien se exportan vía Internet sin que quede registrado en cuentas de producción nacional, especialmente si ello se procesa en el sector informal.

El sector de bienes Tic en la comparación MéxicoBrasil comprende la fabricación de equipo de computación, comunicación, medición y otros, en tanto que el sector de servicios TIC incluye servicios de Internet, información, procesamiento de datos y telecomunicaciones, industria fílmica y de video, industria del sonido, radio y televisión, excepto a través de Internet, y otras telecomunicaciones. El sector de bienes TIC en la comparación México-Estados 
Unidos de América es el mismo que en la comparación México-Brasil, mientras que los servicios TIC incluyen el diseño de sistemas informáticos y servicios relacionados; creación y difusión de contenido exclusivamente a través de Internet; provisión de acceso a Internet; servicios de búsqueda en la red y servicios de procesamiento de información, entre otros, es decir, un universo mucho más focalizado que en el caso anterior (véase el apéndice 1$)^{3}$.

Además de la limitación encontrada para homologar las matrices de los tres países escogidos, el no haber contado con una segunda matriz de insumo-producto (MIP) del mismo año para los tres países significa que dos de ellos se encontraban en un contexto de crisis internacional — Brasil y Estados Unidos de América en 2009- en comparación con México en 2008. En 2009, en los Estados Unidos de América el PIB cayó en $3,5 \%$ y en el Brasil se mantuvo casi estable en - $0,3 \%$, mientras que en México en 2008 este indicador creció $1,2 \%{ }^{4}$. Contraintuitivamente, México tuvo una fuerte contracción en la producción de bienes TIC (arrastrada por los Estados Unidos), a pesar de que su PIB crecía en 2008; en el Brasil este sector tenía un buen desempeño, no obstante el estancamiento económico de dicho país en 2009 y en los Estados Unidos de América ese mismo sector sufría una marcada contracción, pero escalaba tecnológicamente en este último año.

\section{Bienes TIC}

La digitalización de las comunicaciones de la población y las empresas ha permeado a todos los países del mundo. Dado el rezago de los países en desarrollo en este campo, la tasa a la que crece ese mercado es incluso mayor que la de los países industrializados, que ya han logrado una cobertura muy alta en servicios de telefonía móvil, Internet, entre otros (Unión Internacional de Telecomunicaciones (ITU, por sus siglas en inglés)). Sin embargo, qué tan estimulante resulta ese fenómeno con respecto al sector productivo nacional de los países es otro tema. Para muchas naciones en desarrollo, la mayor demanda de bienes y de servicios TIC a raíz de la digitalización puede no tener efecto directo en la producción económica local, si estos se importan. En otros países, el estímulo a la producción de bienes TIC lo genera la incorporación a las cadenas globales

\footnotetext{
${ }^{3}$ Los apéndices 1,2 y 3 se pueden consultar en http://analisisestructural. $\mathrm{mx} / \mathrm{wp}$-content/uploads/2014/07/Ap\%C3\%A9ndiceTIC_ SchatanEnriquez.xlsx.

4 Véanse [en línea] http://data.worldbank.org/indicator/NY.GDP. MKTP.KD.ZG.
}

de valor (CGV) de productos electrónicos, como es el caso de México, aunque el valor agregado (vA) con que contribuyen suele ser limitado si se especializan en eslabones de menor valor de esa cadena, tales como fabricación de insumos genéricos, ensamble y empaque $^{5}$. México, según datos de la Base de Datos Estadísticos de las Naciones Unidas sobre el Comercio de Productos Básicos (COMTRADE), a pesar de ser el quinto exportador mundial de sistemas operativos y de procesamiento de datos, telecomunicaciones, partes y accesorios, y el segundo más importante en pantallas de televisores, su valor agregado era solo de $12 \%$ en 2008 (y había caído en términos absolutos desde 2003) (véase el cuadro 1).

La estrategia del Brasil es diferente de la de México, en el sentido de que ha promovido la expansión de un mercado interno de TIC (es el tercer mercado más grande del mundo para computadoras) y fomentado la integración nacional del sector, de manera que contribuye con más valor agregado a las CGV; la proporción respecto del valor bruto de producción (VBP) era de $25 \%$ en 2009 (véase el cuadro 1), pero depende mucho de las importaciones y además el Brasil no es un exportador competitivo. Uno de los problemas que ha tenido es su especialización en celulares no inteligentes y, en la medida en que los inteligentes desplazan a los anteriores, el Brasil ha pasado de ser un gran exportador a un importante importador y ha revertido pronunciadamente su balanza comercial en este rubro (es más competitivo en electrónica vinculada a la actividad de salud, equipo industrial y a la industria automotriz) (Sturgeon y otros, 2013).

Los Estados Unidos de América están insertos en las CGV, pero se han ido posicionando en los eslabones de mayor vA. La proporción de dicho valor en el vBP del sector de bienes TIC aumentó del 38\% al $63 \%$ de 2003 a 2009 y, aunque en 2009 el vBP cayó en términos absolutos, el va se expandió $30 \%$ (véase el cuadro 2). Después de la crisis del sector electrónico a nivel mundial en 2001, muchos fabricantes de bienes TIC con poco valor agregado se trasladaron de los Estados Unidos de América a China, en procura de reducir costos (Economic Intelligence Unit, 2011).

En síntesis, México, el Brasil y los Estados Unidos de América han experimentado grandes cambios en el sector de bienes TIC, siendo el del Brasil el más dinámico

\footnotetext{
5 Los segmentos de mayor va están al principio de la cadena: los de investigación y desarrollo (I+D), diseño de nuevos productos, fabricación de insumos estratégicos; y en los últimos segmentos de la cadena: fabricación por pedido, servicios postventa y desarrollo de marcas (PRODUCEN-Centro de Inteligencia Estratégica, 2006, citado por Peres y Hilbert, 2009).
} 
(aunque partiendo de niveles muy bajos), al tiempo que ascendía a eslabones más sofisticados de la cadena productiva. Los Estados Unidos de América, por su parte, daban un gran salto hacia los nichos de mucho mayor valor agregado en el período 2003-2009, pero con un retroceso en el VBP. Por último, México retrocedió tanto en el valor agregado como en el VBP (véanse los cuadros 1 y 2).

CUADRO 1

Valor agregado (VA) y valor bruto de producción (VBP) de bienes y de servicios TIC (En millones de dólares de 2005)

\begin{tabular}{|c|c|c|c|c|}
\hline & \multicolumn{2}{|c|}{ México } & \multicolumn{2}{|c|}{ Brasil } \\
\hline & 2003 & 2008 & 2003 & 2009 \\
\hline VA de bienes & & 5472 & 4021 & 12305 \\
\hline VBP de bienes & 44916 & 44988 & 19787 & 48879 \\
\hline VA/VBP de bienes (en porcentajes) & 17 & 12 & 20 & 25 \\
\hline VA de servicios* & 19263 & 28287 & 25987 & 72021 \\
\hline VBP de servicios & 31628 & 44337 & 51405 & 155785 \\
\hline VA/VBP de servicios (en porcentajes) & 61 & 64 & 51 & 46 \\
\hline
\end{tabular}

Fuente: Elaboración propia sobre la base de la MIP de cada país.

Nota: Servicios TIC* abarca un mayor número de ramas que los servicios tic considerados en la comparación entre México y los Estados Unidos de América. Véase el apéndice 2 (pie de página número 3).

CUADRO 2

Valor agregado (VA) y valor bruto producción (VBP) de bienes y de servicios TIC (En millones de dólares de 2005)

\begin{tabular}{|c|c|c|c|c|}
\hline & \multicolumn{2}{|c|}{ México } & \multicolumn{2}{|c|}{ Estados Unidos de América } \\
\hline & 2003 & 2008 & 2003 & 2009 \\
\hline VA de bienes & 7554 & 5472 & 145638 & 189091 \\
\hline VBP de bienes & 44916 & 44988 & 380213 & 298545 \\
\hline VA/VBP de bienes (en porcentajes) & 17 & 12 & 38 & 63 \\
\hline VA de servicios* & 682 & 874 & 184149 & 226455 \\
\hline VBP de servicios & 986 & 1309 & 281915 & 345818 \\
\hline VA/VBP de servicios (en porcentajes) & 69 & 67 & 65 & 65 \\
\hline
\end{tabular}

Fuente: Elaboración propia, sobre la base de la matriz de insumo-producto (MIP) de cada país.

Nota: Servicios TIC* abarca un mayor número de ramas que servicios TIC considerados en la comparación entre México y el Brasil. Véase el apéndice 2 (pie de página número 3).

\section{Servicios TIC}

A medida que la digitalización de la comunicación ha avanzado, las actividades económicas y sociales y la demanda de servicios TIC han experimentado un enorme crecimiento. Aunque estos servicios se vinculan con la operación de los bienes TIC, también responden a la demanda del público, expresada a través de las comunicaciones móviles, el crecimiento de las redes sociales y la expansión de actividades computacionales en la nube (UNCTAD, 2012).

Conviene destacar que el sector de servicios TIC deja una proporción mucho mayor de va respecto del VBP que el de bienes TIC (excepto en el caso de los Estados Unidos de América en 2009). De hecho, el va de los servicios TIC es varias veces mayor que el de los 
bienes TIC en los casos del Brasil y México, y creció aceleradamente sobre todo en el Brasil en el período analizado.

Ello no ocurre cuando se considera la versión focalizada de servicios en México (compatible con la de los Estados Unidos de América), pues el va mexicano es muy pequeño y contrasta notoriamente con el estadounidoense. La mayor conectividad a través de banda ancha y los servicios de informática son un aspecto medular del desarrollo de la economía digital, y los servicios TIC se convierten por lo tanto en un sector productivo importante, pero incipiente en México.

Es necesario aclarar que el rubro de software $e^{6}$ no está incluido en el sector de servicios TIC presentados en los cuadros 1 y 2 . Esto se debe a que en la clasificación utilizada en la comparación entre México y el Brasil se incorpora la producción de software en el sector de servicios profesionales, científicos y técnicos, que es mucho más amplio que el software, lo que dificulta su identificación específica. Algo similar ocurre en la comparación entre México y los Estados Unidos de América.

La creciente incursión en el rubro de software y otros servicios TIC por parte de los países emergentes les abre una puerta a la expansión de una actividad de alta tecnología y elevado vA, en contraste con el sector de manufactura de ensamble. En 2011, el sector de software, por sí solo, era aún muy pequeño en México (1.513 millones de dólares), proporcionalmente también era pequeño en el Brasil (3.069 millones de dólares) y en los Estados Unidos de América, en cambio, alcanzaba a 138.491 millones de dólares (UNCTAD, 2012). El segmento más importante en la producción de software en México es aquel generado dentro de las empresas (63\%), sobrepasando con creces el software producido a la medida por las empresas especializadas del sector (8\%). El resto de la producción de software es principalmente "en paquete" (29\%) (Hualde y Mochi, 2009). En cuanto a su desempeño internacional, los Estados Unidos de América aparecían como el cuarto exportador mundial, mientras que México y el Brasil no estaban entre los primeros 15 (UNCTAD, 2012).

\footnotetext{
${ }^{6}$ La definición de software dada por la Conferencia de las Naciones Unidas sobre Comercio y Desarrollo (UNCTAD) es la siguiente: "Consiste de un conjunto de instrucciones que posibilita la operación adecuada de diversos hardware (computadoras, teléfonos celulares, celulares inteligentes y tabletas, entre otros). En este sentido, el software es el 'cerebro' de los aparatos de 'hardware"” (UNCTAD, 2012, pág. xiii).
}

\section{Empleo y productividad en bienes y servicios TIC}

El comportamiento del empleo en el sector de bienes TIC es consistente con la forma en que los tres países bajo estudio han experimentado su integración a los cambios de la industria de TIC a nivel mundial. Como fue mencionado, la crisis económica de 2008-2009 ocasionó la concentración de la producción de TIC en los eslabones más valiosos de la cadena de valor en los Estados Unidos de América, lo que se tradujo en que este sector perdiera el $30 \%$ de su empleo en el período estudiado, pero mejoraron los salarios y las ganancias de capital sectoriales. México, muy integrado a las CGV y vinculado al mercado de los Estados Unidos de América, perdió empleos (14\%) y fue afectado por la crisis económica mundial, pero sin la flexibilidad de aumentar su productividad y va valor agregado, como su vecino del norte.

Brasil, por su parte, más independiente del mercado internacional y con políticas de estímulo al sector, lograba entre 2003 y 2009 aumentar el empleo (38\%) y la productividad por trabajador (125\%), aunque partía de niveles mucho más bajos de productividad que México en 2003. A pesar del avance, el va por trabajador era aún casi cuatro veces menor que el de los trabajadores estadounidenses, si bien para entonces había sobrepasado la productividad de México en este rubro (véanse los cuadros 3 y 4 ).

De acuerdo con la tendencia internacional, el empleo en el sector servicios TIC tuvo un comportamiento muy dinámico en los tres países estudiados entre 2003 y 2008-2009 y, además, al final de este lapso, esta actividad empleaba a más trabajadores que la producción de bienes TIC (excepto para la versión acotada en el caso de México). De hecho, al comparar México y el Brasil, este último país aparece como un gran empleador: 1,8 millones de personas en 2009, mientras México empleaba 300.000 personas en 2008 (aunque con un VA por trabajador casi tres veces mayor que en el Brasil en 2009). En los Estados Unidos de América, a pesar de la definición mucho más acotada de servicios TIC, esta actividad generaba 1,8 millones de empleos en 2009, superando con creces el empleo en el sector de bienes TIC. La productividad por trabajador en servicios TIC también aumenta en los tres países durante el período estudiado, excepto en México en la versión restringida de estos servicios que incluye a un grupo menor de servicios que el utilizado en la comparación entre México y el Brasil (véanse los cuadros 3 y 4). 
Personal ocupado en sectores de bienes y de servicios TIC (Número de personas)

\begin{tabular}{|c|c|c|c|c|c|c|c|c|}
\hline & \multicolumn{2}{|c|}{ México } & \multicolumn{2}{|c|}{ Brasil } & \multicolumn{2}{|c|}{ México } & \multicolumn{2}{|c|}{ Estados Unidos de América } \\
\hline & Bienes TIC & Servicios TIC & Bienes TIC & Servicios TIC & Bienes TIC & Servicios TIC* & Bienes TIC & Servicios TIC* \\
\hline 2003 & 312763 & 232874 & 200289 & 1399560 & 312763 & 25356 & 1341000 & 1620000 \\
\hline 2008-2009 & 267088 & 299758 & 276205 & 1822993 & 267088 & 34605 & 1125000 & 1778000 \\
\hline
\end{tabular}

Fuente: Elaboración propia sobre la base de la matriz de insumo producto (MIP) de cada país.

Nota: Servicios TIC* abarca un menor número de ramas que Servicios TIC. Véase el apéndice 2 (pie de página 3 ).

CUADRO 4

Valor agregado (VA) por trabajador en sectores de bienes y de servicios TIC (En miles de dólares)

\begin{tabular}{|c|c|c|c|c|c|c|c|c|}
\hline & \multicolumn{2}{|c|}{ México } & \multicolumn{2}{|c|}{ Brasil } & \multicolumn{2}{|c|}{ México } & \multicolumn{2}{|c|}{ Estados Unidos de América } \\
\hline & Bienes TIC & Servicios TIC & Bienes TIC & Servicios TIC & Bienes TIC & Servicios TIC* & Bienes TIC & Servicios TIC* \\
\hline 2003 & 24 & 83 & 20 & 19 & 24 & 27 & 109 & 114 \\
\hline 2008-2009 & 20 & 94 & 45 & 40 & 20 & 25 & 168 & 127 \\
\hline
\end{tabular}

Fuente: Elaboración propia sobre la base de la matriz de insumo producto de cada país.

Nota: Servicios TIC* abarca un menor número de ramas que Servicios Tic. Véase el apéndice 2 (pie de página 3 ).

\section{IV}

\section{Análisis del sector de las TIC basado en matrices de insumo-producto (MIP)}

Es de especial interés en este trabajo analizar la interrelación económica de los sectores TIC con los distintos sectores productivos, tanto a nivel interno como internacional. A medida que las economías tienden a digitalizarse, estos rubros fortalecen su presencia en la oferta y la demanda de los países y tienen efectos tanto directos como indirectos en otros sectores.

\section{Metodología}

Se utilizaron matrices de insumo-producto (MIP) para explorar internamente y a nivel internacional las relaciones intersectoriales. El análisis permitirá observar dichas relaciones y los encadenamientos productivos, incluidos los efectos de arrastre que estos sectores tienen hacia adelante y hacia atrás dentro de las economías.
En primer lugar, se analizaron las relaciones intersectoriales directas de consumo intermedio o compra de insumos por parte de un sector, y de demanda intermedia o ventas de un sector al resto de los sectores.

Para realizar este análisis, se escogieron las matrices internas y la matriz total de interrelaciones sectoriales. Las matrices internas incluyen la matriz de consumo intermedio interno (MCII) y la matriz de demanda intermedia interna (MDII). La MCII registra el valor de las compras que realiza un sector al resto de los sectores productivos dentro del mercado nacional (no incluye importaciones); la MDII registra las ventas de productos nacionales que un sector determinado realiza a los demás sectores productivos (no incluye importaciones). La matriz total de interrelaciones sectoriales refleja las transacciones internas, además de las importaciones. Se 
trata de la matriz de consumo intermedio total (MCIT) y la de demanda intermedia total (MDIT). Cuanto mayor sea la proporción de importaciones en la matriz total de interrelaciones sectoriales, menor será el impacto de ese sector en la economía interna, ya que el estímulo a otros sectores productivos de esas importaciones ocurre en sus economías de origen.

En segundo lugar, se utilizará la metodología de encadenamientos productivos de Dietzenbacher (Dietzenbacher, Van der Linden y Steenge, 1993; Dietzenbacher y Van der Linden, 1997) ${ }^{7}$ para ver de qué manera los sectores TIC inducen efectos de arrastre dentro de las matrices MCII y MDII, tomando en cuenta los efectos directos e indirectos. Se emplea un doble enfoque para su medición: el encadenamiento hacia atrás se determina a partir del modelo de demanda de Leontief (de 1930) con la matriz de absorción de insumos; y el de eslabonamiento hacia adelante se realiza mediante la matriz de oferta de Ghosh (de 1958). Para realizar el cálculo del impacto de las variaciones de demanda y oferta en los demás sectores productivos, se supone que existe una estructura estable de la tecnología y por tanto de insumos intermedios requeridos por cada sector. Los dos enfoques utilizados permiten que los encadenamientos se evalúen como impulsos inducidos por la demanda en un caso y por la oferta en el otro.

Con el fin de hacer el análisis comparativo entre países, se homologaron por una parte los sectores de las MIP disponibles para las economías interna y total del Brasil y México (a 36 sectores) y, por otra, los de los Estados Unidos de América y México (a 57 sectores). Con respecto a 2003, se cuenta con MIP para los tres países y en 2009 para el Brasil y los Estados Unidos de América, mientras que la más reciente para México es de 2008. El no haber contado con una segunda MIP del mismo año para los tres países significa que dos de ellos se encontraban en un contexto de crisis internacional —el Brasil y los Estados Unidos de América en 2009en comparación con México en 2008. En 2009, los Estados Unidos de América experimentaron una caída en el PIB de $-3,5 \%$, el Brasil se mantuvo casi estable en $-0,3 \%$, mientras que en México en 2008 este indicador aumentó $1,2 \% 8$.

\footnotetext{
7 También se puede hacer el cálculo para las MCIT y la MDIT, pero dado que la inclusión de las importaciones no genera mayores encadenamientos nacionales, que es el principal interés en esta sección, no se desarrolló. 8 Indicadores del Banco Mundial [en línea] http://data.worldbank. org/indicator/NY.GDP.MKTP.KD.ZG.
}

\section{Análisis de interrelaciones sectoriales en la matriz de insumo-producto (MIP)}

a) Papel de los sectores de bienes y de servicios TIC en las interrelaciones internas y totales en las MIP de México y el Brasil

La CGV de bienes electrónicos está muy dispersa a nivel internacional, y el hecho de que el comercio de sus insumos intermedios crezca a una tasa mayor que los productos finales señala que la extensión de la cadena sigue ampliándose (Sturgeon y otros, 2013). A la vez, la producción de los distintos eslabones de la CGV han ido cambiando de ubicación geográfica, por lo que la integración nacional de bienes TIC tiene límites en prácticamente todos los países. Sin embargo, existen diferencias relevantes en la especialización de esta industria en cada país, lo que también hace una diferencia en cuanto al va aportado. Como se verá, los servicios TIC ofrecen mayores posibilidades de integración nacional que los bienes TIC. Aquí se indagará el papel de los sectores de bienes y de servicios TIC en las interrelaciones internas y totales de las MIP de México y el Brasil.

Al analizar las MIP de México y el Brasil, llama la atención, primero, que si bien en 2003 el consumo intermedio de los bienes TIC tenía un peso similar en las respectivas matrices, esta situación cambia radicalmente en el período analizado. Así, el valor del consumo intermedio interno de bienes Tic disminuyó en términos absolutos en México en 2003-2008, pero en el Brasil experimentó un crecimiento de alrededor del $100 \%$ en este indicador durante similar período. Al considerar las importaciones (MCIT y MDIT), la relevancia del sector de bienes TIC crece considerablemente en México en ambos años, pero su vínculo con otros sectores es muy limitado (véanse los cuadros 5 y 6). Ello contrasta con el caso del Brasil, donde el componente nacional juega un papel más importante en la gran expansión del consumo y la demanda intermedia (véase el cuadro 5). Este último es un mercado más integrado nacionalmente, pero no deja de formar parte de la CGV, en tanto que el componente importado se ha expandido, especialmente después de 2009 (según la Base de Datos Estadísticos de las Naciones Unidas sobre el Comercio de Productos Básicos (COMTRADE)).

Como contraparte de lo mencionado, México tiene una posición mucho más favorable como exportador de bienes TIC, que constituían alrededor del $20 \%$ del total de sus exportaciones en 2003, porcentaje que se había reducido en 2008, lo que también ocurrió con 
CUADRO 5

México y Brasil: consumo intermedio (compras)

(En millones de dólares de 2005 y porcentajes)

\begin{tabular}{|c|c|c|c|c|c|c|c|c|}
\hline \multirow{4}{*}{ Sector } & \multicolumn{8}{|c|}{ México } \\
\hline & \multicolumn{4}{|c|}{2003} & \multicolumn{4}{|c|}{2008} \\
\hline & \multicolumn{2}{|c|}{ Interna } & \multicolumn{2}{|c|}{ Total } & \multicolumn{2}{|c|}{ Interna } & \multicolumn{2}{|c|}{ Total } \\
\hline & \multicolumn{2}{|r|}{ Porcentaje } & \multicolumn{2}{|r|}{ Porcentaje } & \multicolumn{2}{|r|}{ Porcentaje } & \multicolumn{2}{|r|}{ Porcentaje } \\
\hline 19 & 5719,09 & 1,49 & 37340,44 & 7,10 & 1756,91 & 0,34 & 39561,68 & 5,54 \\
\hline 27 & 10195,21 & 2,66 & 12276,55 & 2,33 & 14125,44 & 2,72 & 16323,76 & 2,29 \\
\hline \multirow{4}{*}{ Sector } & \multicolumn{8}{|c|}{ Brasil } \\
\hline & \multicolumn{4}{|c|}{2003} & \multicolumn{4}{|c|}{2009} \\
\hline & \multicolumn{2}{|c|}{ Interna } & \multicolumn{2}{|c|}{ Total } & \multicolumn{2}{|c|}{ Interna } & \multicolumn{2}{|c|}{ Total } \\
\hline & \multicolumn{2}{|r|}{ Porcentaje } & \multicolumn{2}{|r|}{ Porcentaje } & \multicolumn{2}{|r|}{ Porcentaje } & \multicolumn{2}{|r|}{ Porcentaje } \\
\hline 19 & 10944,64 & 1,76 & 14195,02 & 2,07 & 25508,41 & 1,49 & 32883,19 & 1,76 \\
\hline 27 & 21 186,92 & 3,40 & 22968,36 & 3,34 & 68185,45 & 3,98 & 72980,55 & 3,91 \\
\hline
\end{tabular}

Fuente: Elaboración propia sobre la base de las matrices de insumo-producto (MIP) del Instituto Nacional de Estadística y Geografía (INEGI) para México, y del sistema de matrices de insumo-producto del Núcleo de Economía Regional y Urbana de la Universidad de São Paulo (NEREUS) para el Brasil.

Nota: Sectores:

19: Fabricación de equipo de computación, comunicación, medición y de otros equipos, componentes y accesorios electrónicos.

27: Servicios de Internet, información, procesamiento de datos, publicación y telecomunicaciones.

CUADRO 6

Brasil y México: demanda Intermedia (ventas)

(En millones de dólares de 2005 y porcentajes)

\begin{tabular}{|c|c|c|c|c|c|c|c|c|}
\hline \multirow{4}{*}{ Sector } & \multicolumn{8}{|c|}{ México } \\
\hline & \multicolumn{4}{|c|}{2003} & \multicolumn{4}{|c|}{2008} \\
\hline & \multicolumn{2}{|c|}{ Interna } & \multicolumn{2}{|c|}{ Total } & \multicolumn{2}{|c|}{ Interna } & \multicolumn{2}{|c|}{ Total } \\
\hline & \multicolumn{2}{|r|}{ Porcentaje } & \multicolumn{2}{|r|}{ Porcentaje } & \multicolumn{2}{|r|}{ Porcentaje } & \multicolumn{2}{|r|}{ Porcentaje } \\
\hline 19 & 2193,25 & 0,57 & 33008,15 & 6,28 & 2315,51 & 0,45 & 40171,87 & 5,63 \\
\hline 27 & 13987,30 & 3,65 & 14531,34 & 2,76 & 17361,49 & 3,34 & 17608,60 & 2,47 \\
\hline \multirow{4}{*}{ Sector } & \multicolumn{8}{|c|}{ Brasil } \\
\hline & \multicolumn{4}{|c|}{2003} & \multicolumn{4}{|c|}{2009} \\
\hline & \multicolumn{2}{|c|}{ Interna } & \multicolumn{2}{|c|}{ Total } & \multicolumn{2}{|c|}{ Interna } & \multicolumn{2}{|c|}{ Total } \\
\hline & \multicolumn{2}{|r|}{ Porcentaje } & \multicolumn{2}{|r|}{ Porcentaje } & \multicolumn{2}{|r|}{ Porcentaje } & \multicolumn{2}{|r|}{ Porcentaje } \\
\hline 19 & 5823,43 & 0,94 & 9743,56 & 1,42 & 11988,42 & 0,70 & 21032,57 & 1,13 \\
\hline 27 & 34101,22 & 5,48 & 35896,07 & 5,23 & 109878,82 & 6,42 & 113901,93 & 6,10 \\
\hline
\end{tabular}

Fuente: Elaboración propia sobre la base de las matrices de insumo-producto (MIP) del Instituto Nacional de Estadística y Geografía (INEGI) para México, y del sistema de matrices de insumo-producto del Núcleo de Economía Regional y Urbana de la Universidad de São Paulo (NEREUS) para el Brasil.

Nota: Sectores:

19: Fabricación de equipo de computación, comunicación, medición y de otros equipos, componentes y accesorios electrónicos.

27: Servicios de Internet, información, procesamiento de datos, publicación y telecomunicaciones. 
su superávit. Por su parte, las exportaciones del Brasil representaban la décima parte de las de México en los años considerados y el déficit en la balanza comercial brasileña se cuadruplicó en el período 2003-2009 (Guilhoto y Sesso Filho, 2010).

Las interrelaciones sectoriales del sector de bienes TIC en el interior de las MIP son muy modestas dentro del conjunto de transacciones intermedias internas en México y el Brasil, destacándose el papel del propio sector como mayor demandante de sus bienes intermedios, y en menor medida el de sectores tecnológicamente sofisticados (véanse los cuadros 1.A y 2.A del apéndice 3) ${ }^{9}$.

Con respecto al sector de servicios TIC concerniente a México y el Brasil, que es un sector muy vasto, el análisis de las MIP, entre otros aspectos, indica que este cumple un papel comparativamente más importante que el sector de bienes TIC en la MCII en ambos países. Esta actividad presenta la ventaja de encontrarse más integrada nacionalmente, pues el componente importado es mucho menos relevante en la MCIT de servicios que en la de bienes respecto de ambos países (véanse los cuadros 5 y 6). El sector de bienes TIC realiza compras significativas al de servicios TIC dentro de la MCII en el Brasil, pero en México esta relación es más débil. Por otra parte, el sector de servicios TIC es un relevante destinatario de bienes TIC en ambos países en los años considerados (véanse los cuadros 1.A y 2.A, apéndice 3$)^{10}$. La incorporación de los servicios TIC en forma horizontal en las actividades productivas se aprecia en su papel de proveedor para el resto de los sectores, tanto en la matriz interna como en la total, en ambos casos. Finalmente, el sector de servicios TIC tiene un estrecho vínculo con el propio sector tanto en las compras como en las ventas, pero esta relación es más intensa en el caso del Brasil que en el de México (véanse los cuadros 3.A y 4.A del apéndice 3$)^{11}$.

b) Papel de los sectores de bienes y de servicios TIC en las matrices de insumo producto (MIP) de México y los Estados Unidos de América, internas y totales

La crisis económica de 2009 en los Estados Unidos de América originó una contracción en la producción de bienes TIC y el traslado de diversas empresas a otros países para operar en forma más competitiva. México experimentó un fenómeno similar (aunque menos agudo) a raíz del comienzo de la crisis en los Estados Unidos de América y el mundo en 2008.

Lo que ocurrió con el valor de las transacciones de bienes TIC en la MCII de México y los Estados Unidos de América es consistente con el contexto antes mencionado, ya que estas se debilitaron en el período estudiado, reduciéndose a menos de la mitad en los Estados Unidos y a un tercio en México (véanse los cuadros 7 y 8) (las ventas intermedias internas no fueron tan golpeadas). Al considerar la MCIT, también el consumo intermedio sufrió una gran merma en los Estados Unidos de América, mientras que este no fue el caso en México, donde las importaciones suplieron la caída en este indicador. En cuanto a las ventas intermedias, hubo una disminución en la demanda de bienes TIC por parte de los demás sectores de la economía, especialmente en la MDII de los Estados Unidos de América. Estos resultados probablemente reflejan los distintos momentos en el ciclo económico en que se encontraban México y los Estados Unidos de América en 2008 y 2009, respectivamente.

El sector de servicios TIC, en la clasificación acotada, tiene un papel muy incipiente en todas las interrelaciones intermedias en el caso de México, si se le compara con los Estados Unidos de América (véanse los cuadros 7 y 8). Además, en este último país el sector de servicios TIC se muestra bastante dinámico entre 2003 y 2009 en las matrices de consumo y ventas intermedias, a pesar de que la economía de los Estados Unidos de América estaba en serias dificultades. Puede concluirse que los sectores de bienes TIC y de servicios TIC en dicho país tuvieron comportamientos opuestos en estas matrices entre 2003 y 2009. En México, si bien el sector de servicios TIC avanzó en el período considerado, lo hizo desde una base muy pequeña.

La diferencia en el papel que cumple el sector de servicios TIC en la demanda intermedia en México y en los Estados Unidos de América es abismal. En este último país hay una gran demanda, y en aumento, por parte de los demás sectores de este tipo de servicios, lo que refleja una rápida innovación tecnológica en materia digital en el resto de la economía, mientras que México, en este sentido, se encontraba aún muy rezagado (véanse los cuadros 7.A y 8.A del apéndice 3$)^{12}$.

12 Véase pie de página número 3.

9 Véase pie de página número 3.

10 Véase pie de página número 3.

11 Véase pie de página número 3. 
CUADRO 7

Estados Unidos de América y México: consumo intermedio (compras) (En millones de dólares y porcentajes)

\begin{tabular}{|c|c|c|c|c|c|c|c|c|}
\hline \multirow{4}{*}{ Sector } & \multicolumn{8}{|c|}{ México } \\
\hline & \multicolumn{4}{|c|}{2003} & \multicolumn{4}{|c|}{2008} \\
\hline & \multicolumn{2}{|c|}{ Interna } & \multicolumn{2}{|c|}{ Total } & \multicolumn{2}{|c|}{ Interna } & \multicolumn{2}{|c|}{ Total } \\
\hline & \multicolumn{2}{|r|}{ Porcentaje } & \multicolumn{2}{|r|}{ Porcentaje } & \multicolumn{2}{|c|}{ Porcentaje } & \multicolumn{2}{|r|}{ Porcentaje } \\
\hline 13 & 5719,09 & 1,49 & 37340,44 & 7,10 & 1756,91 & 0,34 & 39561,68 & 5,54 \\
\hline 38 & 273,4 & 0,07 & 303,92 & 0,06 & 407,41 & 0,08 & 437,79 & 0,06 \\
\hline \multirow{4}{*}{ Sector } & \multicolumn{8}{|c|}{ Estados Unidos de América } \\
\hline & \multicolumn{4}{|c|}{2003} & \multicolumn{4}{|c|}{2009} \\
\hline & \multicolumn{2}{|c|}{ Interna } & \multicolumn{2}{|c|}{ Total } & \multicolumn{2}{|c|}{ Interna } & \multicolumn{2}{|c|}{ Total } \\
\hline & & Porcentaje & & Porcentaje & & orcentaje & & Porcentaje \\
\hline 13 & 196112,59 & 2,33 & 238809,40 & 2,62 & 91283,39 & 1,05 & 111071,57 & 1,17 \\
\hline 38 & 88441,25 & 1,05 & 92875,29 & 1,02 & 105730,61 & 1,22 & 113877,88 & 1,20 \\
\hline
\end{tabular}

Fuente: Elaboración propia sobre la base de datos del Sistema de Cuentas Nacionales del Instituto Nacional de Estadística y Geografía (INEGI) y de la Oficina de Análisis Económicos de los Estados Unidos.

Nota: Sectores:

13: Fabricación de equipos de computación, comunicación, medición y de otros equipos, componentes y accesorios electrónicos.

35: Edición de publicaciones y de software, excepto a través de Internet.

36: Industria fílmica y del video, e industria del sonido.

37: Radio y televisión, excepto a través de Internet y otras telecomunicaciones.

38: Servicios de Internet, información y procesamiento de datos.

CUADRO 8

Estados Unidos de América y México: demanda intermedia (ventas) (En millones de dólares y porcentajes)

\begin{tabular}{|c|c|c|c|c|c|c|c|c|}
\hline \multirow{4}{*}{ Sector } & \multicolumn{8}{|c|}{ México } \\
\hline & \multicolumn{4}{|c|}{2003} & \multicolumn{4}{|c|}{2008} \\
\hline & \multicolumn{2}{|c|}{ Interna } & \multicolumn{2}{|c|}{ Total } & \multicolumn{2}{|c|}{ Interna } & \multicolumn{2}{|c|}{ Total } \\
\hline & \multicolumn{2}{|r|}{ Porcentaje } & \multicolumn{2}{|r|}{ Porcentaje } & \multicolumn{2}{|r|}{ Porcentaje } & \multicolumn{2}{|r|}{ Porcentaje } \\
\hline 13 & 2193,25 & 0,57 & 33008,15 & 6,28 & 2315,51 & 0,45 & 40171,87 & 5,63 \\
\hline 38 & 798,67 & 0,21 & 798,67 & 0,15 & 1021,12 & 0,20 & 1021,12 & 0,14 \\
\hline \multirow{4}{*}{ Sector } & \multicolumn{8}{|c|}{ Estados Unidos de América } \\
\hline & \multicolumn{4}{|c|}{2003} & \multicolumn{4}{|c|}{2009} \\
\hline & \multicolumn{2}{|c|}{ Interna } & \multicolumn{2}{|c|}{ Total } & \multicolumn{2}{|c|}{ Interna } & \multicolumn{2}{|c|}{ Total } \\
\hline & \multicolumn{2}{|r|}{ Porcentaje } & \multicolumn{2}{|r|}{ Porcentaje } & \multicolumn{2}{|r|}{ Porcentaje } & \multicolumn{2}{|r|}{ Porcentaje } \\
\hline 13 & 122560,70 & 1,46 & 213700,06 & 2,34 & 102581,32 & 1,18 & 173723,14 & 1,83 \\
\hline 38 & 182177,97 & 2,17 & 186091,80 & 2,04 & 221886,91 & 2,56 & 229668,72 & 2,42 \\
\hline
\end{tabular}

Fuente: Elaboración propia sobre la base de datos del Sistema de Cuentas Nacionales del Instituto Nacional de Estadística y Geografía (INEGI) y de la Oficina de Análisis Económicos de los Estados Unidos.

Nota: Sectores:

13: Fabricación de equipos de computación, comunicación, medición y de otros equipos, componentes y accesorios electrónicos.

35: Edición de publicaciones y de software, excepto a través de Internet.

36: Industria fílmica y del video, e industria del sonido.

37: Radio y televisión, excepto a través de Internet y otras telecomunicaciones.

38: Servicios de Internet, información y procesamiento de datos. 


\section{Encadenamientos de los sectores de bienes y de servicios TIC}

En esta subsección se examina — con la metodología de encadenamientos productivos de Dietzenbacher- hasta qué punto se disemina en la economía una variación en la oferta o en la demanda de bienes y de servicios TIC. Con tal propósito, se consideraron los efectos directos e indirectos de un aumento en la demanda y en la oferta de bienes y servicios TIC en el resto de los sectores productivos, o los encadenamientos que existen entre estos sectores y el resto de ellos.

Para realizar este análisis se compatibilizaron las cifras para México-Brasil y México-Estados Unidos de América, de la manera descrita en la metodología. El resultado del ejercicio realizado muestra que en el caso del Brasil hay un encadenamiento hacia atrás del sector de bienes TIC significativo (1,22 y 1,09 en 2003 y 2009 , respectivamente) y de los servicios TIC (27) hacia adelante (1,50 y 1,68 en 2003 y 2009, respectivamente). Sin embargo, el efecto de arrastre hacia atrás en bienes TIC en ese país se debilita en el período considerado. En cambio, los encadenamientos hacia adelante del sector de servicios TIC brasileño se fortalecen en 2009. Puesto que la digitalización es horizontal, prácticamente todos los sectores, incluso el agrícola, están demandando cada vez más servicios TIC. Si se considera que estos no pueden importarse y aplicarse directamente, se requieren servicios TIC locales de manera que este sector tiene efectos de impulso hacia adelante.

México cuenta con un sector de bienes TIC con encadenamientos internos muy débiles hacia adelante y hacia atrás a los dos niveles de desagregación utilizados, tanto en 2003 como en 2008. En cambio, el sector de servicios TIC tiene encadenamientos hacia adelante bastante fuertes (1,54 en 2003), pero se debilitan en $2008(1,34)$. No hay que perder de vista que este sector, en términos absolutos, tiene aún un valor muy bajo, especialmente al usar la clasificación acotada en la comparación con los Estados Unidos de América. Pero su potencial efecto en el resto de la economía puede ser importante a medida que se expanda la utilización de TIC en todos los sectores productivos.

En cuanto a los Estados Unidos de América, el sector de bienes TIC tenía encadenamientos productivos hacia atrás en $2003(1,07)$, pero en 2009 estos se volvían irrelevantes $(0,64)$, lo que coincide con el fenómeno antes descrito respecto a la reubicación de los eslabones de poco valor agregado de la cadena en países que ofrecían menores costos. Al contrario, el sector de servicios TIC tenía encadenamientos hacia adelante en $2003(1,24)$ y estos se fortalecieron en $2009(1,46)$.

En síntesis, tanto el Brasil como los Estados Unidos de América aparecían con encadenamientos importantes hacia atrás ante un aumento en la producción de bienes TIC en 2003, pero en 2009 este efecto se debilitó en ambos países, aunque en el caso del Brasil el efecto de arrastre hacia atrás seguía siendo significativo. En el caso de México, el efecto de arrastre hacia atrás de bienes TIC era muy débil en 2003 y se debilitó aún más en 2008.

Los encadenamientos hacia adelante del sector de servicios TIC son significativos en los tres países, y se fortalecieron en la medida en que los diversos sectores productivos introducían TIC en su ciclo de producción y requerían de los servicios TIC para operar. Este efecto se robusteció para el Brasil y los Estados Unidos de América entre 2003 y 2009, mientras que se debilitaba en México (pero sigue siendo significativo).

\section{V}

\section{Políticas industriales en el sector de las TIC}

El sector productivo vinculado a las TIC es uno de los más dinámicos a nivel mundial, especialmente en lo que concierne a servicios, $\mathrm{y}$ ha mantenido un relevante crecimiento a pesar del estancamiento de las economías desarrolladas desde 2008. Sin embargo, cada país ha tenido su propia trayectoria y las políticas públicas han influido en alguna medida en su desempeño.

Los Estados Unidos de América han sido el líder mundial de tecnologías de la información y redes, pero a mediados de los años 2000 experimentaban la competencia de otros países como el Japón, algunos países asiáticos y otros de la Unión Europea que avanzaban incluso más rápidamente que ese país en algunos segmentos de estas actividades. Esta situación fue considerada un desafío al liderazgo de los Estados Unidos de América en su investigación y desarrollo (I+D) en materia de TIC. Un informe del Consejo de asesores del Presidente sobre ciencia y tecnología (PCAST, por sus siglas en inglés) 
de 2007 hizo hincapié en este punto y, en 2012, se presentó un plan estratégico para relanzar el liderazgo de los Estados Unidos de América en este ámbito. Este plan consiste en: ampliar la asociación entre humanos y la computación sobre la base de mayores capacidades, disponibilidad y accesibilidad; desarrollar la habilidad de diseñar sistemas seguros y confiables; generar el capital humano necesario para poder operar la innovación y el funcionamiento cibernético (NITRD, 2012). Esta estrategia profundizará la especialización de la economía estadounidense en generar tecnología de frontera para las TIC, especialmente en el área de servicios, mientras que los bienes TIC seguirán sofisticándose. Esta tendencia ya se veía en el período estudiado en secciones anteriores, pero ahora será impulsada mediante una política estatal mucho más activa. Asimismo, el Gobierno de los Estados Unidos de América ha aumentado considerablemente su gasto en infraestructura (Obama, 2015).

En mayor o menor medida, en las políticas públicas se considera prioritario el desarrollo de las TIC en prácticamente todos los países, aunque en el caso de aquellos en desarrollo, como México y el Brasil, las acciones para incentivar al sector de las TIC son mucho más modestas que las mencionadas respecto de los Estados Unidos de América. Pero justamente por ello resulta interesante explorar los pasos adoptados por estas economías de similar nivel de desarrollo, aunque han seguido políticas diferentes a partir de los años noventa.

Si bien las políticas por sí solas no pueden explicar enteramente el desempeño del sector de bienes y de servicios TIC, es innegable que han tenido un papel relevante. Hay otros elementos que sin duda han incidido en la forma en que se ha desarrollado la industria de bienes y servicios Tic en los tres países aquí analizados, tales como su ubicación geográfica, sus acuerdos comerciales internacionales, sus políticas macroeconómicas como por ejemplo las políticas cambiarias, entre otros; no obstante, el estudio no se centrará en estos elementos. A continuación se compararán las políticas de México y el Brasil dirigidas al sector de las TIC, pues su nivel de desarrollo económico es similar.

\section{Políticas para promover el sector de bienes TIC en México y el Brasil}

A objeto de dar impulso a la industria electrónica nacional, México y el Brasil aplicaron políticas públicas comparables en los años setenta y ochenta, como la protección a la industria local y los requerimientos a la inversión extranjera directa (IED) de incorporar un porcentaje mínimo de componentes nacionales, además de proporcionar una serie de incentivos para la expansión de la industria local. Los programas más importantes fueron: en México, el programa de Desarrollo de la Industria de Cómputo y otras Industrias Electrónicas (1983-1988) y en el Brasil, la Ley de Informática (1984) (Peres y Hilbert, 2009).

A la larga, tanto en el Brasil como en México, esta industria protegida, sin metas claras de eficiencia y competitividad, con márgenes de ganancia elevados y un mercado interno restringido, se rezagó. A principios de los años noventa en el Brasil, e incluso antes en México, los productos electrónicos mostraron serios problemas: tenían precios superiores a los internacionales y no podían competir en el mercado mundial. Muchas empresas debieron cerrar o fueron adquiridas por empresas multinacionales.

A partir de los años noventa, las políticas públicas dirigidas a las industrias de bienes y servicios TIC seguidas por el Brasil y México cambiaron en favor de la apertura, pero su enfoque ha sido bastante diferente, aunque ambos países han debido especializarse sobre todo en productos estandarizados (tales como tarjetas de circuitos integrados y productos periféricos, como monitores y, en el caso de México, pantallas planas).

A pesar de una mayor apertura, el Brasil ha mantenido una política industrial dirigida al sector de bienes TIC, además de incentivar la expansión del mercado interno, sin dejar de insertarse en las CGV. Estas políticas son consistentes con algunos resultados analizados en las secciones anteriores: el relativamente mayor vA en esta industria en el Brasil comparado con el de México, así como las interrelaciones sectoriales más intensivas y los efectos de arrastre más fuertes de esta industria en el primer país con respecto al segundo.

Brasil mantuvo una política pública enfocada al escalamiento tecnológico en el más largo plazo. Por ejemplo, en plena apertura, la Ley 8248/91 de 1991 ofrecía exenciones de impuestos a las empresas que se comprometieran a producir localmente ciertos bienes, incorporar contenido local o hacer investigación y desarrollo (I+D) (Peres y Hilbert, 2009; Junqueira y otros, 1999). Las leyes de fomento a la industria han promovido la I+D y el uso generalizado de las TIC a través de la Ley de Innovación de 2004 y la Ley de Bienes de 2005. Esta última, entre otros objetivos, ha estimulado la ampliación del mercado interno mediante la reducción de impuestos a la venta de aparatos electrónicos. El Plan Brasil Mayor (РВM) (2011-2014), también pone énfasis en la I+D de carácter tecnológico para fortalecer la productividad y la tecnología dentro de las cadenas productivas del sector industrial. Además, en este país incluso se exige 
un cierto comportamiento a las compañías extranjeras a fin de fortalecer el mercado y la innovación local. Por ejemplo, en octubre de 2012 se anunció que la introducción de $4 \mathrm{G}$ en el Brasil requería la adquisición del $60 \%$ de los equipos y sistemas fabricados en el país y hasta el $20 \%$ con tecnología nacional (St News, s/f).

A su vez, en México se ha apostado por una mayor apertura y un crecimiento de la industria liderada por las exportaciones. El sector productor de bienes TIC ha sido de alguna manera favorecido por políticas públicas de carácter horizontal, como la Ley de Ciencia y Tecnología (2002) y el Programa Especial de Ciencia, Tecnología e Innovación (2008-2012), así como el Programa de Estímulo a la Innovación, que ha favorecido particularmente al sector de TIC (bienes y servicios), según información de Consejo Nacional de Ciencia y Tecnología (CONACYT). En general, a pesar de que a los esfuerzos del sector público por impulsar la I+D y la innovación en el sector de las TIC le ha faltado una mayor visión de largo plazo, en años muy recientes ha habido un giro hacia el fortalecimiento de la política pública de ciencia, tecnología e innovación (CTI), que ha beneficiado al sector de las TIC. El Programa Especial de Ciencia, Tecnología e Innovación (2014-2018), está teniendo un papel relevante para el desarrollo de las TIC en diversos ámbitos (producción, educación, entre otros).

Las políticas industriales nacionales han sido comparativamente mucho más vigorosas en el Brasil que en México. Pero un análisis a nivel estatal en este último país muestra que ha habido políticas públicas para promover al sector de bienes TIC que han dado buenos resultados. La aglomeración productiva (cluster) del estado de Jalisco es la más importante del sector electrónico y se especializa en la fabricación de equipos de cómputo, con el impulso inicial de IBM y HP. Incluye empresas fabricantes de equipos originales (OEM), de fabricación por contrato y de servicios de fabricación electrónica, un cuantioso número de centros de diseño y cientos de proveedores especializados. También existen más de 150 empresas de software. La industria electrónica en Jalisco transitó de un modelo de alto volumen/baja mezcla a otro de menor volumen/media y alta mezcla, es decir, producción a menor escala y bienes de mayor vA (Padilla, 2005; Palacios, 2008). El sector empresarial y el sector público en conjunto desarrollaron una estrategia para que Jalisco dejara de ser un estado exclusivamente maquilador en la electrónica y pasara a ser generador de tecnología y conocimiento en este rubro, después de la crisis en esa industria en 2001 a nivel mundial (Programa Estatal de Ciencia y Tecnología del Estado de Jalisco en 2003). Los resultados fueron considerables, pues en Jalisco surgió la manufactura de diseño original (ODM) y el estado se convirtió en el centro de diseño de semiconductores más importante de América Latina y el Caribe (ALC) (Palacios, 2008; Secretaría de Economía, 2012). De todas formas, estos esfuerzos locales no alcanzaron a generar una diferencia significativa a nivel nacional en cuanto al avance tecnológico de este sector.

En el Brasil se han adoptado medidas concretas para ampliar el mercado interno, como el desarrollado por el Plan Nacional de Banda Ancha que dará conexión a 70 millones de estudiantes, junto con medidas para abaratar los sistemas operativos. Si esto último ocurre, se espera que haya un gran estímulo a la producción de semiconductores, que es el sector "meta" de la estrategia TIC en el Plan Brasil Maior (PBM), junto con el rubro de software $^{13}$. En México también se han desarrollado medidas recientes para expandir el mercado interno, aunque su propósito es más bien acelerar la penetración de la tecnología digital en todo el país, lo que puede resultar estimulante para el sector productivo, especialmente con respecto a los servicios TIC (IT Decisions, 2012).

\section{Políticas para promover el rubro de software y el sector de servicios TIC en México y el Brasil}

Las actividades del software y otros servicios TIC han adquirido importancia a partir de los años noventa tanto en México como en el Brasil, pues —en primer lugar - la rápida innovación tecnológica de la industria de hardware ha requerido la incorporación creciente y cambiante de software en sus equipos. Segundo, el funcionamiento de una amplia gama de empresas de muy diversos sectores económicos necesitan programas digitales o su adaptación. Tercero, prácticamente todas las instituciones de gobierno tienden a digitalizarse, de manera que la gobernanza electrónica, que incluye tareas de hacienda, salud, educación, aduaneras, y otras, exige programas propios que respondan a sus características particulares.

Brasil tiene el mercado y la producción de software más grande de ALC, a lo que contribuyó una ambiciosa política de estímulos a su creación en los años noventa. La mayoría del software responde a la demanda del mercado nacional, pero tempranamente ese país tuvo como meta alcanzar una competitividad en el mercado internacional. Para ello, en 1993 se creó la Asociación para la Promoción de la Excelencia del Software Brasileño

\footnotetext{
13 IT Decisions, 2012 [en línea] http://itdecs.com/2011/08/brazilianindustrial-policy-what-it-means-for-it/.
} 
(SOFTEX), que junto con el gobierno ha logrado darle un pronunciado impulso a dicha industria. Este programa también contemplaba la formación de centros regionales para apoyar la colaboración entre pequeñas y medianas empresas (pymes) productoras de software, la formación de capital humano, además de proveer los vínculos internacionales para la exportación de software. Desde 2008 está vigente una nueva política de promoción de software y TIC que coloca a este sector entre los prioritarios para el gobierno.

Al igual que para la política de hardware, en México la de software y servicios TIC fue impulsada por asociaciones público-privadas en los estados, especialmente en el de Jalisco. Esta política sirvió de importante punto de referencia para el programa federal de software: Programa de Desarrollo del Sector de Servicios de Tecnologías de Información (PROSOFT), programa que se enfoca en apoyar el rubro de software, los servicios de tecnología de la información, la tercerización de procesos de negocio, y la contratación externa de los procesos y medios creativos digitales ${ }^{14}$.

El énfasis de la política del Brasil ha consistido en hacer partícipe de este sector a grupos importantes de la población y, a la vez, contribuir a mejorar sus capacidades y estimular la creatividad en software. Este es el caso del programa PC Conectado (de 2005), que consistía en entregar un millón de computadoras de bajo costo a los estudiantes de las escuelas, con un software de código abierto, en lugar de software propietario, con el fin de estimular el desarrollo de software local y abaratar costos (UNCTAD, 2012). Esta medida coincide con la estrategia de fortalecer un mercado interno de TIC y crear un ambiente propicio para el desarrollo local de software.

En México se han dado pasos muy recientes para lograr una digitalización más incluyente, sobre todo a través de la reforma constitucional en telecomunicaciones de 2013, en que se reconoce el derecho de toda la población de acceder a las TIC, incluidas la banda ancha e Internet. El proyecto México Conectado habilitará la Estrategia Digital Nacional, facilitando el acceso a Internet en los espacios públicos, incluidos escuelas, clínicas, ayuntamientos, centros comunitarios, bibliotecas, parques y plazas, entre otros.

14 Prosoft 2.0 [en línea] http://www.prosoft.economia.gob.mx/ apoyosprosoft/.
Tanto México como el Brasil cuentan con programas de apoyo financiero al sector, pero este último país ha destinado fondos mucho más cuantiosos a este fin. El programa PROSOFT, a cargo del Banco de Desarrollo del Brasil (BNDES) provee financiamiento de largo plazo para cubrir hasta el $85 \%$ de la inversión, dentro de un cierto límite, además de otros mecanismos de financiamiento para esta actividad. El programa TI Maior de 2012 considera un fondo de 250 millones de dólares para desarrollar la industria del software, y espera poder canalizar 750 millones de dólares adicionales para I+D en este campo. Este nuevo programa estimulará a las empresas para que desarrollen software relevante para las industrias brasileras, tales como la de extracción de petróleo y gas, la agricultura, el gobierno, la provisión de capital semilla para los start-ups en software, y respaldo a los esfuerzos por atraer IED que establezca centros de I+D en el área de TIC del país (Newsblog, 2012).

El programa PROSOFT en México puede proporcionar apoyos financieros en las áreas de capacitación, certificación, habilitación y equipamiento tecnológico, normas y modelos, adopción y producción de TI, innovación, comercialización, estudios para desarrollar capacidades de negocio, entre otras. También hay un descuento del $30 \%$ sobre el pago anual del impuesto sobre la renta para cualquier industria que haga I+D (CONACYT). La industria del software en México también puede beneficiarse del Fondo Nacional Emprendedor de la Secretaría de Economía y del financiamiento que dan los gobiernos estatales, que ofrece distintos tipos de apoyo en forma de subsidios a servicios o infraestructura, pero también apoya a las pymes en su digitalización.

$\mathrm{Al}$ igual que en el caso de los bienes TIC, la política industrial enfocada al software en el Brasil tiene como estrategia posicionar al sector como un productor tecnológicamente sofisticado y competitivo a nivel nacional e internacional. Una de las formas prácticas de superar las barreras de acceso a la tecnología es a través de asociaciones público-privadas con empresas de punta en esta industria. Por ejemplo, habrá una asociación entre el Gobierno del Brasil e Intel para promover la I+D en el sector de software (durante el período 2013-2018). México también empieza a dar apoyos más focalizados a la industria de software, por ejemplo, en forma de capital semilla o de riesgo a través del programa HIR PyME. 


\section{VI}

\section{Reflexiones finales}

El sector productivo de bienes y servicios TIC tiene un papel creciente en las economías a medida que los países avanzan hacia una sociedad digital. Este fenómeno ocurre a distintos ritmos entre sectores y países, pero sin duda es un acontecimiento mundial.

México está inserto en las CGV de TIC, y es un exportador importante, especialmente de bienes TIC, pero su participación en estas cadenas es de bajo va, con algunas excepciones. Al mismo tiempo, las interrelaciones sectoriales internas han sido muy limitadas para el sector de bienes TIC y su efecto de arrastre en el resto de los sectores bastante débil. Estos resultados alcanzados mediante un análisis de las MIP son consistentes con la política pública que ha predominado para este sector (aunque hay diversos otros elementos que han influido en su desempeño). Más que una política industrial dirigida al sector de bienes TIC, se apostó por la atracción de la IED dadas las ventajas del país en costos, proximidad a los Estado Unidos de América, y la firma del Tratado de Libre Comercio de América del Norte (TLCAN). Con el avance de la dispersión geográfica de las cadenas productivas de la industria, muchas empresas fabricantes de equipos originales (OEM) o fabricantes por contrato (CM) se instalaron en México, lo que se consideró un éxito, aunque estas no trajeron los segmentos de producción tecnológicamente de punta al país, ni contribuyeron a transferir tecnología. A la vez, se volvió muy vulnerable a los vaivenes de las decisiones de las grandes empresas multinacionales y del mercado mundial.

Los Estados Unidos de América mostraron una trayectoria mucho más flexible que México en el sector de bienes TIC ante la crisis de 2001-2003 de este sector. Se reposicionaron en las CGV en forma notoria, aumentando considerablemente su va (aunque perdiendo muchos empleos, pero mejorando su calidad). En ese país también se debilitaron los efectos de arrastre. Desde mediados de los años 2000, los Estados Unidos de América han desarrollado una estrategia para recuperar su empuje en las actividades de investigación y desarrollo e innovación en el sector de las TIC, a fin de mantener su liderazgo mundial y fortalecer su manufactura. El hecho de que las cinco multinacionales en TIC originarias de los Estados Unidos de América hagan más del 50\% de la I+D e innovación en TIC en el mundo, también es un elemento que considerar para atraer a esas empresas a que desarrollen algunas de estas actividades en México.
La política pública del Brasil ha sido más cercana a la de los países asiáticos, que han planeado paso a paso el desarrollo del sector y con una apertura controlada. Pero este país aún no ha logrado penetrar los mercados internacionales ni insertarse en los eslabones más avanzados en esta industria, si bien destaca por sus esfuerzos por integrar a su industria de bienes TIC a nivel nacional, sin dejar de pertenecer a las CGV. En el período estudiado (2003-2009), el Brasil logró profundizar considerablemente las relaciones intersectoriales internas y cuenta con efectos de arrastre significativos, a la vez que ha generado más empleos y un aumento en su productividad (aunque empezando de niveles muy bajos). Este país ha desplegado políticas industriales enfocadas en este sector, favoreciendo la consolidación del mercado interno y brindando importantes apoyos a la industria local. No obstante, no ha logrado la competitividad internacional y sufre de un creciente déficit externo, además de destinar muchos recursos fiscales a financiar los estímulos al sector.

Uno de los propósitos del Brasil es colocarse en los nichos más avanzados de semiconductores (sector "meta"), que es la industria que encabeza la actividad innovadora en los bienes TIC a nivel internacional, donde dominan los Estados Unidos de América y Europa. Pero tener la mirada en el sector de semiconductores puede fructificar, pues actualmente este abarca el 33\% del mercado total del sector electrónico mundial ${ }^{15}$. Además, estos productos tendrán una creciente demanda a medida que aumente la necesidad de microprocesadores, dada la convergencia tecnológica de productos tales como reproductores y grabadoras de audio y video, cámaras digitales, televisores digitales y teléfonos celulares. Una apuesta algo arriesgada, pero importante de considerar para un país como México.

En el período muy reciente, México ha tendido a cambiar considerablemente la política dirigida al sector de las TIC (bienes y servicios). Ha tomado medidas para mejorar la infraestructura requerida para una penetración mucho mayor de la digitalización en la sociedad y las empresas, ha cambiado el marco regulatorio para garantizar una mayor competitividad en el sector y ha

15 Semiconductores, equipo médico e industrial, computación, comunicaciones, electrónica de consumo (Secretaría de Economía, 2012). 
ido diseñando una política más enfocada al sector de las TIC.

Los resultados del presente estudio indican que el sector de servicios TIC tiene importantes diferencias con el de bienes TIC en México y también en el Brasil y los Estados Unidos de América, siendo mucho más prometedor que el de bienes. Su gran dinamismo es consistente con el avance acelerado hacia una sociedad digitalizada. La demanda en aumento de los servicios TIC se explica no solo porque el sector de hardware requiere un creciente componente de software y múltiples servicios TIC, sino también porque en la medida en que todos los demás sectores productivos se tecnifican a través de las TIC, también incorporan estos servicios.

En el análisis de las MIP se observó que tanto en México como en los otros dos países considerados la industria de servicios TIC tiene mayores interrelaciones sectoriales internas que la de los bienes TIC, y mostró ser una fuente creciente de empleos. En la comparación entre México y los Estados Unidos de América del sector de servicios TIC, que solo se centra en diseño de sistemas informáticos y servicios de Internet, se aprecia una enorme brecha, que va mucho más allá del contrastante tamaño entre las dos economías. Sin embargo, visto como una oportunidad, el desarrollo de este sector en México es muy prometedor en cuanto a generación de va y empleos.

Las políticas de México y el Brasil dirigidas a impulsar al sector de servicios TIC han sido más recientes. En el Brasil han sido más amplias y vigorosas que en México, aunque a nivel estatal, y este país ha tenido éxitos importantes en que las alianzas público-privadas han sido centrales, pero se necesita un impulso mucho mayor. Tanto México como el Brasil tienen que hacer un mayor esfuerzo en mejorar su competitividad en servicios TIC, puesto que sus exportaciones son aún incipientes y el ejemplo de la India muestra que el potencial de un país en desarrollo, con una sólida política enfocada a este sector, es mucho mayor que el alcanzado hasta ahora por los dos países latinoamericanos mencionados. La India ha dado un respaldo especial al fortalecimiento de su capital humano. Cabe notar que se trata de un sector al que los Estados Unidos de América están dando un gran apoyo para avanzar aceleradamente, ya que es el que marca en gran medida el escalamiento tecnológico de las TIC.

\section{Bibliografía}

CEPAL (Comisión Económica para América Latina y el Caribe) (2013), "Estrategias de TIC ante el desafío del cambio estructural en América Latina y el Caribe: balance y retos de renovación", Documento de Proyecto (LC/W.534), Santiago.

Dietzenbacher, E. y J.A. van der Linden (1997), "Sectoral and spatial linkages in the EC production structure", Journal of Regional Science, vol. $37, \mathrm{~N}^{\circ} 2$, Wiley.

Dietzenbacher, E., J.A. van der Linden y A.E. Steenge (1993), "The regional extraction method: EC input-output comparisons", Economic Systems Research, vol. 5, No 2, Taylor \& Francis.

Economic Intelligence Unit (2011), Investment for the Future: Benchmarking IT Industry Competitiveness 2011, Business Software Alliance [en línea] http://globalindex11.bsa.org/keyfindings/\#continued-us-leadership.

Foro Económico Mundial (2014), The Global Information Technology Report 2014, Ginebra.

Guilhoto, J.J.M. y U.A. Sesso Filho (2010), "Estimação da matriz insumo-produto utilizando dados preliminares das contas nacionais: aplicação e análise de indicadores econômicos para o Brasil em 2005", Economia \& Tecnologia, año 6, vol. 23, octubre-diciembre [en línea] http://www.usp.br/nereus/wpcontent/uploads/Metodologia-guilhoto-sesso-EA-2010.pdf.

Hilbert, M. y P. López (2012), "How to measure the world's technological capacity to communicate, store, and compute information", International Journal of Communication, vol. 6 , University of Southern California.

Hualde, A. y P. Mochi (2009), "México: producción interna e integración mundial", Desafíos y oportunidades de la industria del software en América Latina, P. Bastos Tigre y F. Silveira (eds.), Comisión Económica para América Latina y el Caribe (CEPAL)/Mayol Ediciones.

INEGI (Instituto Nacional de Estadística y Geografía) (2013), "Cuenta de bienes y servicios", Banco de Información Económica [en línea] http://www.inegi.org.mx/sistemas/bie/?idserPadre $=102$ 00110\#D10200110.
IT Decisions (2012), "Brazil industrial policy: what it means for IT" [en línea] http://itdecs.com/2011/08/brazilian-industrial-policywhat-it-means-for-it/.

Junqueira, A.J. y otros (1999), From Industry Protection to Industry Promotion: IT Policy in Brazil, Irvine, California, Universidad de California, octubre [en línea] http://crito.uci. edu/papers/1999/brazil-case-10-99.pdf.

McNamara, K. (2008), The Global Textile and Garments Industry: The Role of Information and Communication Technologies (ICTs) in Exploiting the Value Chain, Washington, D.C., Banco Mundial.

Newsblog (2012), "High hopes for Brazilian science funding windfall" [en línea] http://blogs.nature.com/news/2012/08/ high-hopes-for-brazilian-science-funding-windfall.html.

Niebel, T. (2014), "ICT and economic growth. Comparing developing, emerging and developed countries" [en línea] http://www.iariw. org/papers/2014/NiebelPaper.pdf.

NITRD (The Networking and Information Technology Research and Development Program) (2012), The Networking and Information Technology Research and Development (NITRD) Program 2012 Strategic Plan, Arlington [https://www.nitrd. gov/Pubs/strategic_plans/2012_NITRD_Strategic_Plan.pdf].

Obama, B. (2015), "Remarks by the President in State of the Union Address" [en línea] https://www.whitehouse.gov/the-pressoffice/2015/01/20/remarks-president-state-union-addressjanuary-20-2015.

ocDE (Organización para la Cooperación y el Desarrollo Económicos) (2014), Measuring the Digital Economy. A New Perspective, París.

(s/f), "OECD Broadband Portal" [en línea] http://www.oecd. org/sti/broadband/OECDbroadbandportal.htm.

ORBA (Observatorio Regional de Banda Ancha) (2011), Boletín, $\mathrm{N}^{\mathrm{O}} 2$, agosto.

Padilla, R. (2005), La industria electrónica en México: diagnóstico, prospectiva y estrategia, Ciudad de México, Instituto 
Tecnológico Autónomo de México (ITAM) [en línea] http:// cec.itam.mx/docs/Electronica_Mexico.pdf.

Palacios, J.J. (2008), "Alianzas público-privadas y escalamiento industrial. El caso del complejo de alta tecnología de Jalisco, México", serie Estudios y Perspectivas, № 98 (LC/L.2897-P),

Ciudad de México, sede subregional de la CEPAL en México.

Peres, W. y M. Hilbert (eds.) (2009), La sociedad de la información en América Latina y el Caribe: desarrollo de las tecnologías y tecnologías para el desarrollo, Libros de la CEPAL, $\mathrm{N}^{\circ} 98$ (LC/G.2363-P), Santiago, Comisión Económica para América Latina y el Caribe (CEPAL).

PRODUCEN-Centro de Inteligencia Estratégica (2006), "Presentación sobre cluster de electrónica", Baja California, noviembre.

Secretaría de Economía (2012), Monografía: industria electrónica en México, Ciudad de México, octubre [en línea] http:// www.economia.gob.mx/files/comunidad_negocios/industria_ comercio/monografia_industria_electronica_Oct2012.pdf.

ST News (s/f), "Brasil mantendrá política industrial sobre 4G" [en línea] http://www.signalstelecomnews.com/index. $\mathrm{php} /$ contenidos/3029-brasil-mantendra-la-politica-industrialsobre-4g.

Sturgeon, T.J. y M. Kawakami (2010), "Global value chains in the electronics industry: was the crisis a window of opportunity for developing countries?", Policy Research Working Paper, $\mathrm{N}^{\circ}$ 5417, Washington, D.C., Banco Mundial.

Sturgeon, T.J. y otros (2013), Brazilian Manufacturing in International Perspective: A Global Value Chain Analysis of Brazil's Aerospace, Medical Devices, and Electronics Industries, septiembre [en línea] http://www.cggc.duke.edu/pdfs/CNI_ Brazil_GVC_Report_Final_2013-09-05.pdf.

UNCTAD (Conferencia de las Naciones Unidas sobre Comercio y Desarrollo) (2012), Informe sobre la economía de la información 2012. La industria del software y los países en desarrollo, Ginebra [en línea] http://unctad.org/es/ PublicationsLibrary/ier2012_es.pdf. 